УДК 338

\title{
OPPORTUNITY TO INTRODUCE PRODUCTS OF SMALL AND MEDIUM ENTERPRISES TO THE MARKETS OF DEVELOPED COUNTRIES
}

\section{Sugarsuren E. ${ }^{1}$}

\section{Mongolian University and Science and Technology, Ulaanbaatar, Mongo- lia}

Many small and medium enterprises are willing to expand their market and export their products. However, it is common for them to not be able to achieve the desired results and sell in the global market. It is becoming increasingly common for developed countries to focus on product quality and safety as key criteria. To ensure quality and safety should implement internationally recognized standards. To overcome this challenge, it is important for quality management institutions and researchers to work together to develop quality management recommendations that are specific to the country through the research and analysis of global standards.

Keywords: Global Food Safety Initiative, small and medium enterprises, safety and quality standard.

What are the main challenges for small and medium enterprises in developing countries to sell their products to developed countries? Many small and medium enterprises are willing to expand their market and export their products. To do this, companies invest in training of human resources, upgrading equipment, and learning from the experience of foreign competitors. As a result, the products have good design, concept and a strong sales and marketing policy. However, it is common for them to not be able to achieve the desired results and sell in the global market. So what could be the solution to this problem?

Suppose manufacturers want to supply their products to North American and European countries, and they want to supply products by signing contracts with large stores, retail chains in those countries. Manufacturers have all the resources, including machinery, equipment, technology, materials and specialists. However, the question of how to meet the import requirements of developed countries and how to meet the criteria for selecting

\footnotetext{
${ }^{1}$ Sugarsuren E - Ph.d candidate of Graduate School of Business, Mongolian University and Science and Technology)
} 
suppliers by partner companies remains. It is not enough for a manufacturer to offer any low price, short delivery time and best product. It is becoming increasingly common for developed countries to focus on product quality and safety as key criteria. When choosing a supplier, companies first examine whether they are able to provide quality assurance. If this criterion is met, other factors, such as price, cost, and solution, are considered later. Let's look at how to ensure quality assurance. GFSI sets quality and safety criteria for the global food industry (Global Food Safety Initiative, 2000).

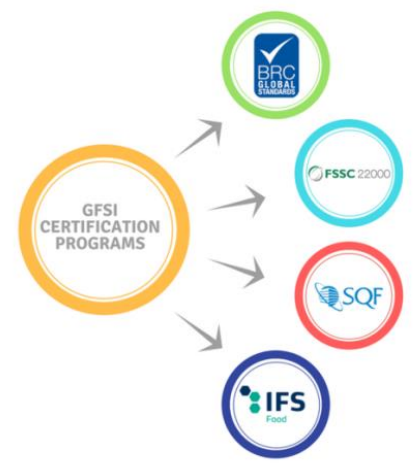

Figure 1 - Standards recognized by GFSI

This organization defines the Food Safety and Quality Benchmark in order to protect food quality and safety. The organization operates by recognizing the standards owners, such as FSSC 22000, SQF, and BRC, are compliant with the benchmark. The most commonly used standards in the food industry are BRC and SQF. BRC and SQF standards are recognized by GFSI and are developed and updated based on GFSI recommendations (GFSI, 2020). There are also certification bodies that issue certificates by monitoring compliance with the standard. These organizations inspect and evaluate compliance with the standard and issue appropriate levels of certificates. Companies select standards that are appropriate to their business and implement them as appropriate. After that, it will be audited by an authorized certification body and will have a GFSI-recognized certificate.

It is very important to get this certificate. For example, each country has legal requirements for imports. In other words, in order to market your product in another country, you will need to meet the import requirements of that country (Agency, 2019). With the implementation of the above standards, companies become ready to meet the import criteria of the most 
countries. This is because import criteria are often milder than GFSI criteria. Therefore, if the GFSI standard is introduced, it will be easier to meet the import criteria.

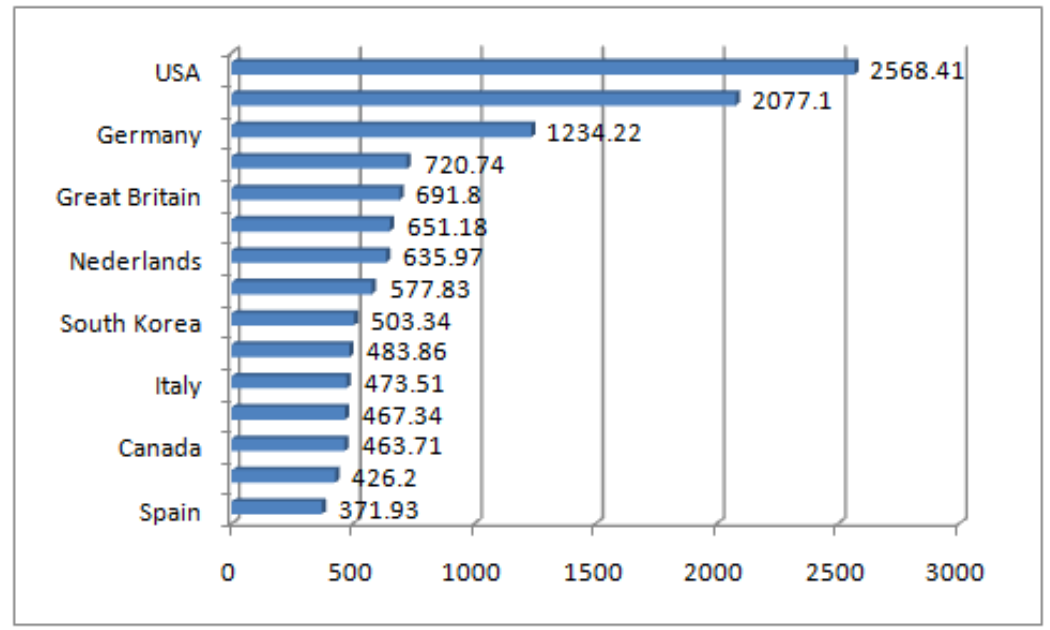

Figure 2 - List of leading importing countries - 2019 (Plecher, 2020)

The next priority is to find a partner. SMEs will definitely need a partner to place their products in other countries. It is important that your partner does not doubt the quality of your product. The GFSI recognized certificate is proof of quality assurance. If a competitor does not have a certificate, there is a high probability that the company with the compliance will be selected. This will make it easier to become a supplier. For example, if you want to sell frozen products on Amazon, the leading sales channel, you will be asked for a GFSI certificate (Amazon, 2018). If a GFSI certificate is not available, it can be demonstrated that a quality management system equivalent to the certificate has been implemented.

The third advantage is that a certification or quality management system is also helpful if you plan to sell your product directly under your own brand name. For example, sales of products with a standard label are higher than sales of a product without a label. In 2013, university researchers, in collaboration with Diversey Consulting (Sealed Air), the Consumer Goods Forum, and GFSI, surveyed 15,000 GFSI-certified organizations and found that about 50\% saw growth in their sales. (Crandall, 2017)

So what are food safety and quality standards? It is a documented quality management system. Like all other management systems, it has 
components, and quality management can only be achieved if the organization is able to provide a unified management of its policies, planning and business processes, and the quality of each of the related workflows.

So how will developing countries implement this standard? Certification bodies for the above standards often operate in developed countries (Rahmat, 2016). Systematic audits can be contracted out to these organizations, but this is often financially challenging for developing countries. Therefore, the easiest solution is for countries to meet international standards by studying these standards in detail based on their specifics and making recommendations that can be implemented domestically based on GFSI recommendations.

In the language of the country, recommendations can be made to meet international requirements that are cheaper than foreign consulting services and do not cause logistical problems, so that small and medium-sized enterprises can be audited by external certification bodies when they feel they implemented the standard requirements. This will provide an opportunity to enter the international market with less language and financial difficulties.

To this end, developing countries need to work with professional organizations and researchers to develop recommendations that are easy to implement for small and medium-sized enterprises through a detailed study of international standards and analysis of specific domestic requirements.

This shows that we need to assure the quality and safety of SME products in order to launch products in foreign markets, especially in developed countries. To ensure quality and safety should implement internationally recognized standards. However, developing countries, especially small and medium-sized enterprises of these countries, face language and financial difficulties in adopting and getting certified. To overcome this challenge, it is important for quality management institutions and researchers to work together to develop quality management recommendations that are specific to the country through the research and analysis of global standards.

\section{References}

1 Agency, C. F. (2019, December 02). Importing food to Canada: a stepby-step guide. Canada.

2 Amazon. (2018, Jul 31). Amazon Seller Central. Retrieved Oct 05, 2020, from Chilled and frozen foods: https://sellercentral.amazon.com/gp/help/external/GWAH98EVB875C4BD

3 Crandall, P. G. (2017). Impact of the Global Food Safety Initiative on Food Safety Worldwide: Statistical Analysis of a Survey of International Food Processors. Journal of Food Protection, 80. 
4 GFSI. (2020, Jan). Progress Benchmark \& TE Applications List. Retrieved Oct 02, 2020, from Global Food Safety Initiative: https://mygfsi.com/wp-content/uploads/2019/09/CPO_printableversion_A3_20200424.pdf

5 Global Food Safety Initiative. (2000). Retrieved October 01, 2020, from https://mygfsi.com/who-we-are/overview/

6 Plecher, H. (2020, Aug 25). Leading import countries worldwide 2019. Retrieved Oct 10, 2020, from Statista: https:// www.statista.com/statistics/268184/leading-import-countries-worldwide/

7 Rahmat, S. (2016). Challenges of Developing Countries in Complying Quality and Enhancing Standards in Food Industries. ScienceDirect, 446-451. 